\title{
Effect of Sweeteners on the Microstructure of Yogurt
}

\author{
Zahur Z. HAQUE and Kayanush J. ARYANA \\ Department of Food Science and Technology, Southeast Dairy Foods Research Center, MAFES, Mississippi State, University, MS 39762.
}

Received May 2, 2001; Accepted December 19, 2001

\begin{abstract}
The objective was to determine the effect of a peptide sweetener, Aspartame, compared to a carbohydrate sweetener, sucrose, on the microstructure of yogurt. Microstructure was determined by transmission and scanning electron microscopy. Without the sweeteners, casein micelles, that make up the yogurt matrix, were observed in single longitudinal polymers. When Aspartame was used, casein micelles formed double longitudinal polymers. In comparison sugar caused casein micelles to form clusters. Data show that type of sweetener impacts state of association of casein micelles and thus effects microstructure.
\end{abstract}

Keywords: cultured, dairy, fermentation, structure, sweetener

Principal component analysis of yogurt revealed high consumer acceptability for sweetness characteristics and lower consumer acceptability for samples with plain yogurt character (Barnes et al., 1991). Hence consumers want the sweetness in yogurt but health reasons dictate decreased intake of calories and reduction of sugars. To decrease calories in yogurt, artificial sweeteners have been incorporated (Nabros \& Gelandi, 1986; Keating \& White, 1990). Farooq and Haque (1992) reported that nonfat yogurts with Aspartame, a popular peptide based sweetener, had half the calories per serving compared to regular yogurt containing 3.25\% fat and 4\% sucrose. Mozaffar and Haque (1992) and Haque (1993) have shown that amphipathic peptides (like Aspartame) effect protein-protein association, which is a primary requisite during gel formation. On the other hand sugars such as sucrose are traditionally used by enzymologists to stabilize enzyme proteins (Choi \& Kosikowski, 1985). Such hydrophilic solutes impact water structuring and hence influence protein-protein association (Kalab \& Harwalkar, 1972). This in turn may impact the amount of entrapped water or pore dimensions. The size of pores of the casein micelle network is a major factor affecting susceptibility of yogurt to syneresis (Harwalkar \& Kalab, 1986). Various factors such as heating of milk, total solids content, $\mathrm{pH}$, lactic acid bacteria and thickening agents have been reported to affect the microstructure of yogurt (Kalab et al., 1983). It would be interesting to see the effect of a peptide sweetener, Aspartame, compared to a carbohydrate sweetener, sucrose, on yogurt gel network formation.

Yogurt was made as described earlier by Farooq and Haque (1992) with slight modification. Yogurt mixes were prepared in 1 $l$ batches. Fluid skim milk with $9 \%$ milk solids not fat (MSNF) was obtained from the Mississippi State University Dairy Plant. Other ingredients added on weight per volume basis were $0.5 \%$ modified food starch, 3\% non fat dry milk (NDM), $0.02 \%$ Aspartame (NutraSweet Co., Deerfield, IL), and 3\% maltodextrin or 3\% sugar. The overall total solids (TS) content was $15.5 \%$ (Table 1). Every effort was taken to keep TS constant to avoid its

Approved as journal article \#9851 of the Miss. Agric. \& For. Exp. Sta., Mississippi State, MS 39762. Funded by MAFES Project \#3153

E-mail: haque@ra.msstate.edu impact on microstructure (Kalab et al., 1983; Harwalkar \& Kal$\mathrm{ab}, 1986)$. Ingredients were throughly mixed in fluid skim milk heated to $60^{\circ} \mathrm{C}$ and homogenized at 35.15 and $140.62 \mathrm{~kg} / \mathrm{cm}^{2}$. This was followed by batch pasteurization at $85^{\circ} \mathrm{C}$ for $30 \mathrm{~min}$ and rapid cooling to $38^{\circ} \mathrm{C}$. Thawed culture concentrate (\# 380) comprising of Lactobacillus bulgaricus and Streptococcus thermophilus (Chr. Hansen=s Lab. Milwaukee, WI), were then added to inoculate the base mixes that were then poured into $250 \mathrm{~g}$ cups and incubated at $38^{\circ} \mathrm{C}$. After approximately $10 \mathrm{~h}$, or when the $\mathrm{pH}$ reached 4.4 , the incubation was terminated by placing cups in an ice bath followed by refrigeration at $5^{\circ} \mathrm{C}$.

Yogurt samples for scanning electron microscopy were taken from the center of the cup. Yogurt was cut with the help of a sharp blade into $1 \mathrm{~mm}^{3}$ pieces. Sample processing was according to Aryana and Haque (2001). Samples were fixed in 1.4\% glutaraldehyde (Sigma, St. Louis, MO) overnight in a refrigerator. These were then washed in six changes of water over a two min period. Samples were dehydrated in a graded series of ethanol $(35,50$, 70 , and $95 \%$; 15 min per change). Dehydration was continued in $100 \%$ ethanol (Electron Microscopy Sciences, Fort Washington, PA), (three changes over one hour) followed by critical point drying (Polaron critical point dryer, Ted Pella, Inc., Redding, CA) and mounted with double sided carbon sticky tape (Electron Microscopy Sciences) on aluminum stubs (Electron Microscopy Sciences). This was followed by sputter coating (Polaron sputter coater, Watford, UK). Samples were viewed Cambridge S 300 SEM (Leo, Electron Microscopy Inc. Thornwood, NY).

Sample processing for transmission electron microscopy was also according to Aryana and Haque (2001). Yogurt was cut with the help of blade into $1 \mathrm{~mm}^{3}$ pieces. Samples were then fixed in $1 \%$ glutaraldehyde (Sigma) in $0.1 \mathrm{M}$ potassium phosphate buffer (Fisher Scientific, Fair Lawn, NJ) (pH 7.2) overnight in a refrigerator, rinsed three times (10 min each) in buffer $(0.1 \mathrm{M}$ potassium phosphate buffer $\mathrm{pH}$ 7.2) and post fixed in $1 \%$ osmium tetroxide (Fisher Scientific) for $30 \mathrm{~min}$. The fixed specimens were rinsed three times in distilled water, stained with $1 \%$ aqueous uranyl acetate (Fisher Scientific) for $30 \mathrm{~min}$ and rinsed three times over a $15 \mathrm{~min}$ period in distilled water. Dehydration was in $35,50,70,95 \%$ ethanol for $15 \mathrm{~min}$, and finally in $100 \%$ ethanol 
(Electron Microscopy Sciences) for an hour (three changes). The dehydrated samples were placed in propylene oxide (Electron Microscopy Sciences) (two changes over an hour). Infiltration was done. These were then placed overnight in an oven at $70^{\circ} \mathrm{C}$ for $15 \mathrm{~h}$. Thin sections were cut using a Reichert-Jung ultramicrotome (Cambridge Instruments Inc. Buffalo, NY) and collected on formvar (Electron Microscopy Sciences) coated copper grids (Ernest F. Fullam, Inc. Schenectady, NY) and stained with uranyl acetate (Fisher Scientific) and Reynolds lead citrate (J.T.

Table 1. Ingredients for yogurt (\% by weight).

\begin{tabular}{lccc}
\hline \multicolumn{1}{c}{ Ingredients } & $\begin{array}{c}\text { Yogurt with } \\
\text { sugar }\end{array}$ & $\begin{array}{c}\text { Yogurt with } \\
\text { aspartame }\end{array}$ & $\begin{array}{c}\text { Yogurt without } \\
\text { sweetener }\end{array}$ \\
\hline Fluid skim milk solids & 9 & 9 & 9 \\
Non fat dry milk & 3 & 3 & 3 \\
Starch & 0.5 & 0.5 & 0.5 \\
Maltodextrin & 0 & 2.98 & 3 \\
Sugar & 3 & 0 & 0 \\
Aspartame & 0 & 0.02 & 0 \\
\hline
\end{tabular}

Baker Chemical Co. Phillipsburg, NJ) (Reynold, 1963). Sections on the grid were washed in distilled water, air dried and in a JEOL 100 CX II TEM (JEOL, Peabody, MA).

The experiment was conducted using a completely randomized design. Three replications were conducted.

Transmission electron microscopic (TEM) observations revealed that in absence of any sweetener, the yogurt matrix was predominantly casein micelles arranged in longitudinal polymers (Fig. 1A). Yogurt made with Aspartame caused casein micelles to arranged themselves in double longitudinal polymers (arrows) (Fig. 1B) indicating an increased tendency to polymerize. Aspartame is a methyl ester of L-aspartic acid and L-phenylalanine (Isralow, 1983; Vetsch, 1985). Thus it is a highly soap-like molecule with distinctly separate hydrophobic and hydrophilic zones. Such molecules influence hydrophobic interactions that play an important role during thermal gelation (Tanford, 1980; Busk, 1984).

Yogurt made with sugar showed a matrix in which casein micelles associated in form of clusters (arrows) in some spots
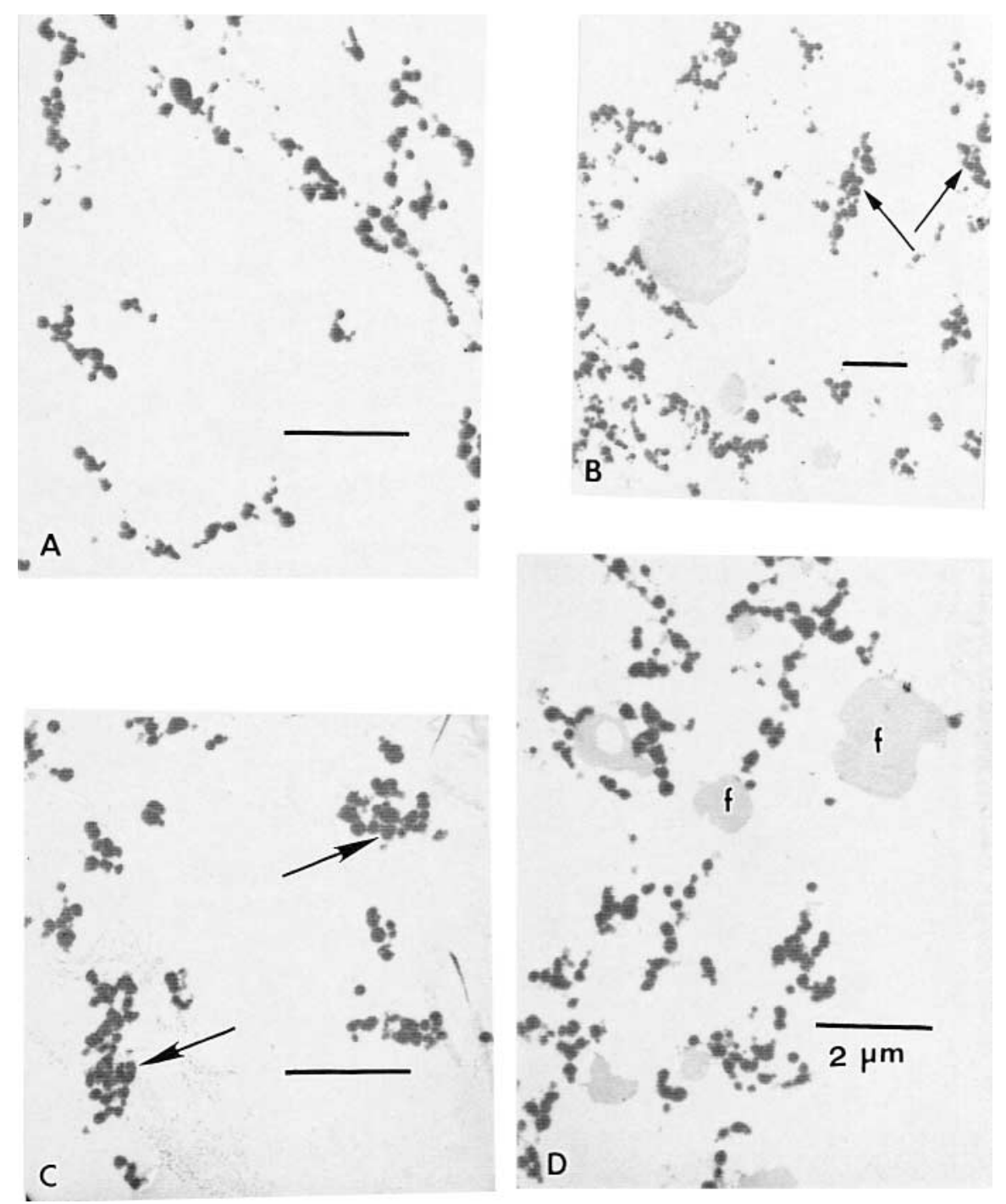

Fig. 1. Transmission electron micrograph of A) yogurt made from skim milk in absence of sweetener. Casein micelles arranged in longitudinal polymers. Bar represents $2 \mu \mathrm{m}$. B) yogurt in presence of aspartame. Casein micelles seen in double longitudinal polymers. Bar represents $2 \mu \mathrm{m}$. C) yogurt in presence of sugar. Casein micelles in clusters in some spots. Bar represents $2 \mu \mathrm{m}$. D) yogurt made from whole milk in absence of sweetener. Fat globules (f) seen associated with casein micelles. 

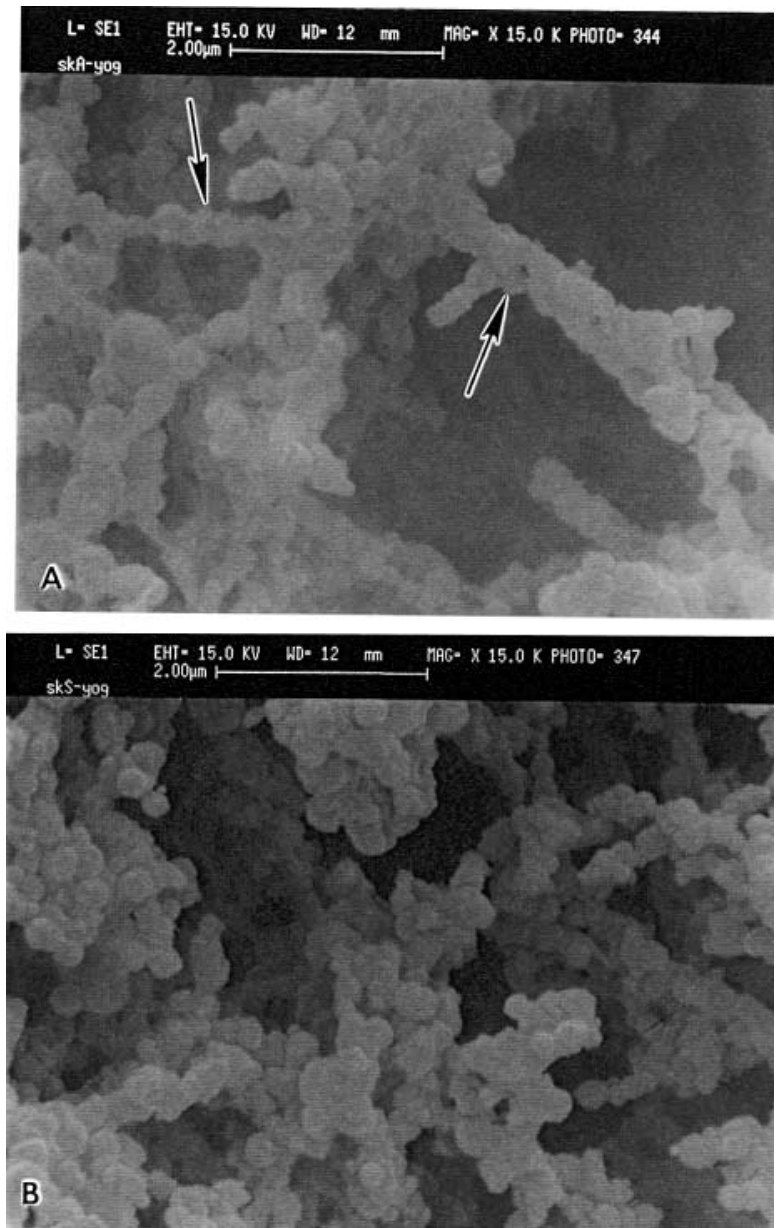

Fig. 2. Scanning electron micrograph of A) yogurt made with aspartame. Casein micelles predominantly in double longitudinal polymers (arrows). B) yogurt made with sugar. Casein micelles seen in clusters in some spots.

(Fig. 1C) causing the matrix to form large void spaces implying greater entrapment of water.

The difference between yogurts made from skim milk and whole milk was the relative absence of fat globules in skim milk (Fig. 1A) compared to whole milk (Fig. 1D). These fat globules (f) were associated with the casein micelles. Aguilera and Kinsella (1991) reported compatibility of fat globules and casein micelles in protein matrix of filled gels and in whey protein isolate gel matrix (Yost \& Kinsella, 1992). Tamime et al. (1984) reported that yogurts made with anhydrous milk fat had shorter casein micelle chains compared to yogurts made with protein based fat substitute Simplesse 100.

Number of rows of casein micelles were higher in yogurt with sweeteners compared to control. Scanning electron microscopic (SEM) observations confirmed the TEM observations. Casein micelles were predominantly in double longitudinal polymers (arrows, Fig. 2A) when Aspartame was used. Sugar caused casein micelles to cluster (Fig. 2B).

Kalab and Emmons (1975), when studying the effects of thickening agents on the microstructure of yogurt, reported that starch and carrageenan contributed a considerable change to the microstructure. They observed yogurt with $0.4 \%$ carrageenan gave clusters of casein micelles connected with thin fibers. The present data show that use of Aspartame, even at the small usage level of $0.2 \%(\mathrm{w} / \mathrm{v})$ compared to $3 \% \mathrm{w} / \mathrm{v}$ usage level for sucrose, caused significant changes in the microstructure of yogurt gels.

\section{References}

Aguilera, J.M. and Kinsella, J.E. (1991). Compression strength of dairy gels and microstructural interpretation. J. Food. Sci., 56, $1224-1228$.

Aryana, K.J. and Haque, Z.U. (2001). Effect of commercial fat replacers on the Microstructure of low-fat Cheddar cheese. Int. J. Food Sci. Tech., 36, 169-177.

Barnes, D.L., Harper, S.J., Bodyfelt, F.W. and McDamiel, M.R. (1991). Correlation of descriptive and consumer panel flavor ratings for commercial prestirred strawberry and lemon yogurts. J. Dairy Sci., 74, 2089-2099.

Busk, G. C., Jr. (1984). Polymer-water interactions in gelation. FoodTechnol., 38, 59-60, 62, 64.

Choi, H.S. and Kosikowski, F.V. (1985). Sweetened plain and flavored carbonated yogurt beverages. J. Dairy Sci., 68, 613-619.

Farooq, K. and Haque, Z.U. (1992). Effect of sugar-esters on the textural properties of nonfat low calorie yogurt. J. Dairy Sci., 75, 2676-2680.

Haque, Z.U. (1993). Influence of milk peptides in determining the functionality of milk proteins: A review. J. Dairy Sci., 76, 311-320.

Harwalkar, V.R. and Kalab, M. (1986). Relationship between microstructure and susceptibility to syneresis in yogurt made from reconstituted nonfat dry milk. Food Microstruct., 5, 287-294.

Isralow, S. (1983). Beyond better nutrition. Horizons, 2, 22-27.

Kalab, M. and Emmons, D.B. (1975). Milk-gel structure. IV. Microstructure of yogurts in relation to the presence of thickening agents. J. Dairy Res., 42, 453-458.

Kalab, M. and Harwalkar, V.R. (1972). Milk Gel Structure. I. Application of scanning electron microscopy to milk and other food gels. $J$. Dairy Sci., 56, 835-842.

Kalab, M., Allan-Wajtas, P. and Phillips-Todd, B.E. (1983). Development of microstructure in set-style nonfat yogurt-a review. Food Microstruct., 2, 51-66.

Keating, K.R. and White, C.H. (1990). Effect of alternative sweeteners in plain and fruit flavored yogurts. J. Dairy Sci., 73, 54-62.

Modler, H.W. and Kalab, M. (1983). Microstructure of yogurt stabilized with milk proteins. J. Dairy Sci., 66, 430-437.

Mozaffar, Z. and Haque, Z.U. (1992). Casein hydrolysate: 3. Some functional properties of hydrophobic peptides synthesized from casein hydrolysate. Food Hydrocolloids, 5, 573-579.

Nabros, L.O. and Gelandi, R.C. (1986). Alternative Sweeteners. Marcel Dekker, Inc., New York, NY.

Reynolds, E.S. (1963). The use of lead acetate at high pH as an electron opeque stain in electron microscopy. J. Cell. Biol., 17, 208-212

Tamime, A.Y., Kalab, M. and Davies, G. (1984). Microstructure of setstyle yogurt manufactured from cow's milk fortified by various methods. Food Microstruct., 3, 83-92.

Tanford, C. (1980). In "The Hydrophobic effect," Formation of micelles and biological membranes, 2nd ed, John Wiley \& Sons, New York, NY, 30-41.

Vetsch, W. (1985). Aspartame: technical considerations and predicted use. Food Chem., 16, 245-250.

Yost, R.A. and Kinsella, J.E. (1992). Microstructure of whey protein isolate gels containing emulsified butterfat droplets. J. Food. Sci., 57, 892-897. 